\section{Cells in the Urine}

SIR,-The article by Dr. A. E. Gent and his colleagues (2 November, p. 294) is of great interest. A minor criticism, both of this and of much other work on urine cell excretion, is that the authors assume that the small cells in the urine which are not derived from polymorphs originate in the renal tubules. The authors do not describe these cells, but since staining is necessary to distinguish them they are presumably of much the same size as polymorphs. Yet examination of a histological section of the kidney shows that the majority of renal tubular cells are much larger than this. It is true that such small cells can be obtained by scraping the cut surface of the kidney, ${ }^{1}$ but under these circumstances contamination with blood is unavoidable, however much the surface is first washed with saline.

Some work which I have done ${ }^{23}$ suggests that many of these small cells are in fact lymphocytes or mononuclear cells. Cells from the renal tubules can be obtained by microdissection, and when suspended in saline or urine show a cytoplasm which stains in an irregular fashion with methylene blue, as well as hyaline droplet formation. The presence of lymphocytes and monocytes in the urine was known to workers in the earlier part of this century, but appears recently to have been overlooked. ${ }^{4}$ The practical consequences of this is that an increase in the numbers of small round cells in the urine should not necessarily be taken as evidence of damage to the tubules.

A further point which should be given prominence by authors who work with the stain devised by Prescott and Brodie ${ }^{1}$ is that its main constituent is metabolized in the body to a carcinogen. ${ }^{5}-\mathrm{I}$ am, etc.,

\section{S. T. G. ButTerworth.}

Pathology Department,

Western General Hospital,

Edinburgh 4.

\section{REFERENCES}

Prescolt, L. F., and Brodie, D. E., Lancet, 1964

2 Butterworth, S. T. G., M.D. Thesis, Cambridge, 1966.

Butterworth, S. T. G., Brit. F. Urol., to be published.

Quensel, U., Nord. med. Arkiv., 1918, 50, 319,

\section{Training of Surgeons}

SIR,-I much appreciated $\mathrm{Mr}$. Neville Stidolph's humane article on the training of surgeons (9 November, p. 379) but I was disappointed to read that the selection for consultant training during a period of general professional training might be based on examination of the basic medical sciences. A certain level of knowledge in physiology, pathology, and anatomy underlies the work of every doctor, each subject to a varying extent dependent on the eventual specialty. It is right and fair that an examination of a consultant candidate's knowledge in these subjects should form part of a demonstration that he is fit for the work he wishes to undertake. But this is a different matter from making the would-be consultants compete in these subjects.

British education is bedevilled by examinations in which the candidate shows himself excellent at subject $\mathrm{A}$ in order that he may be trained for subject B. For while the principles of A may have relevance and be the foundation of $B$, the more precise details of A may find no application. But in order that he should be among those who qualify to proceed the details have for a while to be known.

It could not be denied that the candidate who, for example, knew the structures and life times of the compounds in the citric acid cycle knew more than his friend who could only give their names. Maybe he is the man to be given higher training, but has not his time and effort been put to other than the best use that can be devised ?-I am, etc.,

\section{Twickenham}

J. E. P. Simpson.

Middlesex.

\section{Lithium in Psychiatric Disorders}

SIR,-Your editorial on the use of lithium in psychiatric disorders (2 November, p. 271) will be welcomed, particularly as it reviews the impressive study of Angst and his coworkers. ${ }^{1}$ This work may lead to a much wider use of lithium, as it offers the hope at least that this drug may be of value in the control of recurrent depressions. If this is so, it is to be hoped that the drug will be used with the caution that you advise.

I have used lithium for 10 years and while side-effects are few they may occasionally be alarming and dangerous. Accordingly, this is most certainly a drug which should only be used with a proper awareness of the possible side-effects and adequate laboratory controls. My own experience would suggest that the drug should be withdrawn immediately should slurring of speech, coarse tremor, difficulty in walking, or drowsiness be encountered. The drug should not be used without laboratory facilities for carrying out serum lithium estimations and serum electrolyte studies. It should be remembered that a brisk short course of E.C.T. ${ }^{3}$ remains the best treatment for mania, and lithium should be reserved for those cases who are unfit for E.C.T. or for those particularly difficult conditions such as rapidly recurring mania and depression.-I am, etc.,

\section{N. BERLYNe.} Oldham and District General Hospital,
Oldham, Lancs.

\section{REFERENCES}

Angst, J., Dittrich, A., and Grof, P., paper read at the annual meeting of the Royal MedicoPsychological Association, Plymouth, July 1968.
Somatic Treatments in Psychiatry Kalinowsky, Somatic Treatments in Psychiatry, Kalinowsky,
L. B., and Hoch, P. H., New York and London, ig61.

SIR,-I was surprised to read in a leading article (2 November, p. 271) entitled "Lithium in Psychiatric Disorders" the following:

"Relapses during lithium medication were significantly fewer than during the equivalent period before treatment. Subdividing the patients with diagnostic groups, the prophylactic effect was least in the recurrent depressive illnesses $(P=0.03)$ and more effective in the bipolar disorders. Most surprising was the high prophylactic effect of lithium in schizo-affective disorders $(P<0.001)$."
As such, the implication is that the lower $P$ value of 0.001 allows one to deduce a greater therapeutic efficacy. To anyone with any knowledge of statistics this is of course nonsense. Worse still for anyone without such knowledge it is grossly misleading. Moreover, even if relapses are " significantly fewer" the real question is whether the decrease in the number of relapses is not just statistically significant, but whether it is sufficiently great to warrant the use of a drug which, as you admit in the article, has been implicated as a cause of neurological damage. -I am, etc.,

Friern Hospital,
London N.11.

G. Silverman.

SIR,-Difficulty in diagnosis was encountered in the case of an Indian (Hindu) carpenter aged 36 years, who came to the outpatient department complaining of backache and joint pains. Results of routine investigations were normal, and he did not improve on physiotherapy and analgesics. As patients from the tropics present special problems, he was questioned in detail about previous residence, and it transpired that he had lived from birth up to the age of 17 in Porbandar on the Indian coast north-west of Bombay (the region from which Weingarten reported 81 cases of pulmonary tropical eosinophilia in 1943). ${ }^{1}$ From there he went to live in Mombasa, migrated thence to England in 1965, returned to Porbandar in 1967, and after three months arrived back in London at the end of that year.

A month after his first attendance here pain in the lumbar region had worsened, and it extended down the backs of his thighs to both calves. His E.S.R. was $8 \mathrm{~mm} . / \mathrm{hr}$., $\mathrm{Hb} 16.6$ g. $/ 100$ ml., W.B.C. 24,000, eosinophils $9,120 / \mathrm{cu}$. mm. A fortnight later bronchospasm was observed, he admitted to cough (worse at night), and a blood count showed W.B.C. 36,000 , eosinophils $24,840 / \mathrm{cu}$. $\mathrm{mm}$. Chest $x$-ray showed miliary shadows with one or two larger foci and was unchanged a week later, when blood count showed W.B.C. 40,000 , eosinophils $28,000 / \mathrm{cu}$. mm., and the filarial complement-fixation test with Ascaris antigen gave a strongly positive result. Hetrazan (diethylcarbamazine) was given at once in doses of $800 \mathrm{mg}$. daily for six days, followed by $400 \mathrm{mg}$. daily for six days. Chlorpheniramine maleate, paracetamol, and amylobarbitone were then used, as the patient complained of aches all over. He had a small hydrocele which had been present since excision of inguinal lymph nodes in Mombasa, and this suddenly increased in size. It was tapped $(50 \mathrm{ml}$.), but the fluid proved negative for microfilariae, and several faecal examinations were negative for parasites. Eosinophilia decreased after seven days on Hetrazan to $8,625 / \mathrm{cu}$. mm., and was 784 cu. mm. (W.B.C. 9,800/cu. mm.) four weeks later. By this time the patient was gaining weight, the chest radiograph was improved, the cough cured, and the titre of the filarial complement-fixation test beginning to fall ( 1 in 160). Three weeks later the titre had fallen to 1 in 30 and the eosinophil count was below $200 / \mathrm{cu}$. mm. The patient's understand- 
ing of English was poor and his statements vague, but at the conclusion of the medical interlude reported here he appeared to be in statu quo-that is, a sufferer from lumbago.

The laboratory findings in pulmonary tropical eosinophilia are fourfold: high eosinophilia, high titre in the complement-fixation test, absence of microfilaraemia, and a histological picture of eosinophilic granulomata focused on microfilariae, which show evidence of death before fixation, ${ }^{23}$ and whose remnants are probably represented by $M K$ bodies." The resemblance of our case (incubation time 18-30 weeks) to the third infection (incubation time 25 weeks) in the volunteer reported by Buckley and Wharton ${ }^{s}$ becomes closer on the assumption that the focal reaction in the hydrocele which followed diethylcarbamazine treatment is indicative of previous filarial infection. The possibility arises that, in addition to zoonotic infection by filarial species parasitic to animals as in the first two infections of the volunteer reported by Buckley, ${ }^{6}$ sensitization by a previous filarial infection might also cause the high level of antibody to the nematode lipid antigen used in the test by Robinson and Christian. ${ }^{8}$ In our experience such levels have been reached only in pulmonary tropical eosinophilia (not in filariasis) and in visceral larva migrans. ${ }^{2}$ Moreover, if the high antibody level is itself regarded as the lethal factor, causing the microfilariae to arrive in the capillaries in a dead or moribund condition, this might account not only for the eosinophilic granulomata but also for the characteristic absence of microfilariae in the venous blood.

This case is of interest as one in which iatrogenic Loeffler's syndrome was at first suspected (though only Disprin and Panadol had perhaps been taken), but the use of the complement-fixation test gave the true diagnosis, subsequently confirmed by a detailed history (Unde Venis ? ${ }^{7}$ ) and by the effect of Hetrazan.

I should like to thank Dr. E. T. Bassadone for permission to report on his case.

-I am, etc.,

\section{G. L. RoBINSON.}

Devonport Laboratory,

Dreadnought Seamen's Hospital
Greenwich, London S.E.10.

\section{REFERENCES}

1 Weingarten, R. J., Lancet, 1943, 1, 103.

2 Beaver, P.' C., Bull. Soc. Path exot., 1962, 55 s Webb, J. K. G., Job, C. K., and Gault, E. W., Lancet, 1960, 1, 835.

- Meyers, F. M., and Kouwenaar, W., Geneesk,

s Buckley, J. J.' C., and Wharton, R. H., F.

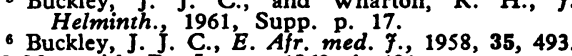

- Buckley, J. C., E. Afr. med. F,

8 Robinson, G. L., and Christian, M., J. clin. Path., 1968, 21,' 394.

\section{Circular Hospital Building}

SIR,-_Seeing blueprints for a 14-storey circular building with a central well housing toilet facilities and lifts, and a corridor from which 10 or 12 bedrooms opened on each floor, presented an idea for a new type of hospital ward. Every room had an outside window with a clear view. We have built three hospital blocks on a circular plan (Fig. 1). The first, providing a total of $\mathbf{3 0}$ surgical beds, has central nursing stations in which medicines, linen, and equipment are stored and office work completed, and designed so that a patient's trolley can be wheeled in for dressings. Even at periods when nursing staff is at a minimum, all patients can be easily observed by this arrangement. On the lower floor, radial partitions gave easy individual curtaining for seriously ill patients. The advantages noted were that there was no wasted space, less walking for nurses, and maximum space between bed-heads, rendering droplet infec-

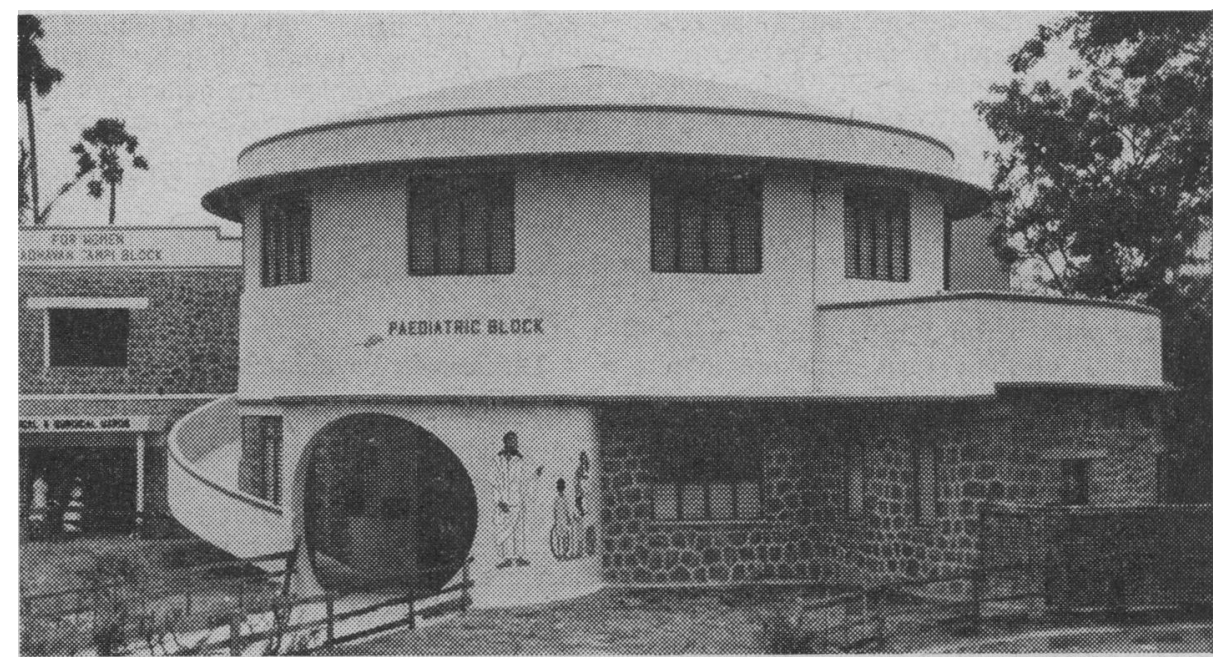

FIG. 1

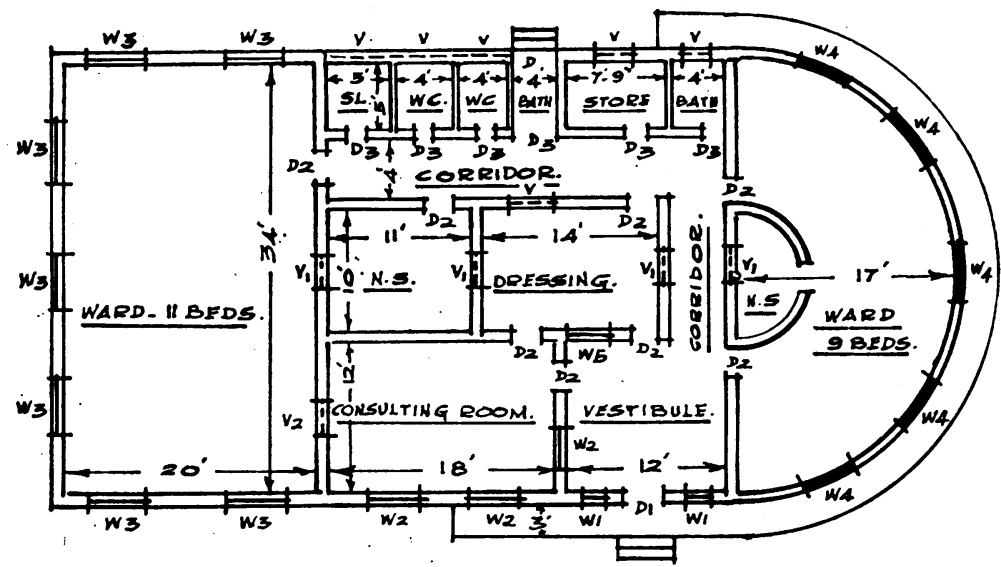

Fig. 2 Ground floor plan

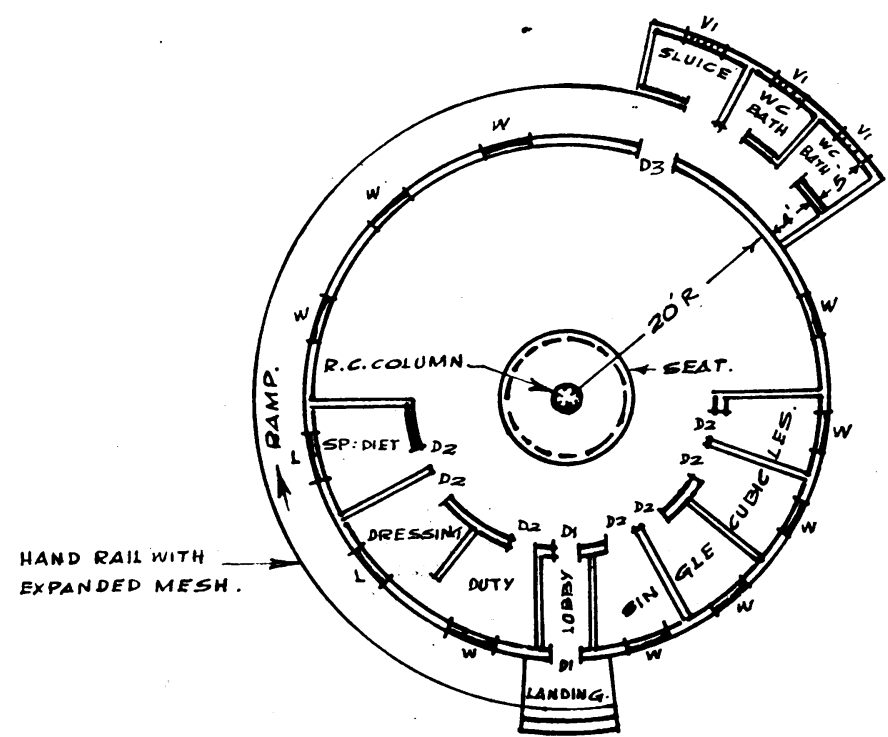

Fig. 3 Ground floor plan permissible gradient allows wheelchairs and trolleys to transport patients, thus obviating ophthalmic department which had to be fitted to an existing site. Though the building is basically rectangular, one end is semicircular with a half-circle ward on the ground floor and operating-theatre complex on the second.

tion less likely. A $4 \mathrm{ft}$. ramp at standard 